Defraeye T., Blocken B., Carmeliet J. (2013), Influence of uncertainty in heat-moisture transport properties on convective drying of porous materials by numerical modelling, Chemical Engineering Research and Design 91 (1), 36-42. http://dx.doi.org/10.1016/i.cherd.2012.06.011

\title{
Influence of uncertainty in heat-moisture transport properties on convective drying of porous materials by numerical modelling
}

Thijs Defraeye ${ }^{\mathrm{a}, \mathrm{b}, *}$, Bert Blocken $^{\mathrm{c}}$, Jan Carmeliet ${ }^{\mathrm{d}, \mathrm{e}}$

${ }^{a}$ VCBT / MeBioS, Department of Biosystems, Katholieke Universiteit Leuven, Willem de Croylaan 42, 3001 Heverlee, Belgium

${ }^{b}$ Laboratory of Building Physics, Department of Civil Engineering, Katholieke Universiteit Leuven, Kasteelpark Arenberg 40, 3001 Heverlee, Belgium

${ }^{c}$ Building Physics and Systems, Eindhoven University of Technology, P.O. Box 513, 5600 Eindhoven, The Netherlands

${ }^{d}$ Chair of Building Physics, Swiss Federal Institute of Technology Zurich (ETHZ), Wolfgang-Pauli-Strasse 15, 8093 Zürich, Switzerland

${ }^{e}$ Laboratory for Building Science and Technology, Swiss Federal Laboratories for Materials Testing and Research (Empa), Überlandstrasse 129, 8600 Dübendorf, Switzerland

\section{Keywords}

convective drying; porous material; heat-moisture transport properties; uncertainty; stochastic ; material

\footnotetext{
* Corresponding author. Tel.: +32 (0)16321618; fax: +32 (0)16322966.

E-mail address: thijs.defraeye@biw.kuleuven.be
}
Abbreviations:
CDRP constant drying rate period
CHTC convective heat transfer coefficient
CMTC convective moisture transfer coefficient
DDRP decreasing drying rate period
HAM heat-air-moisture transfer
MCS Monte Carlo simulation
TP-PA transport-property parameter analysis
$\mathrm{RH}$ relative humidity 
Defraeye T., Blocken B., Carmeliet J. (2013), Influence of uncertainty in heat-moisture transport properties on convective drying of porous materials by numerical modelling, Chemical Engineering

Research and Design 91 (1), 36-42. http://dx.doi.org/10.1016/i.cherd.2012.06.011

\begin{abstract}
The influence of uncertainties in heat-moisture transport properties, due to measurement errors and material heterogeneity, on the numerical simulation results of convective drying of two capillary-saturated porous materials is investigated by a transport-property parameter analysis (TP-PA), based on the Monte Carlo method. Here, the heat-air-moisture transfer model is evaluated many times, each time using a random set of one or multiple input parameters (i.e. transport properties), by which a stochastic model output is generated. The propagation of these transport-property uncertainties to the hygrothermal behaviour of the drying system is evaluated by statistical analysis of the model simulation output. The spread on the hygrothermal response is found to be strongly material dependent and is related to the dominant mode of moisture transport in the material, i.e. liquid or vapour transport. The TP-PA results clearly indicate that uncertainties in the heat-moisture transport properties can lead to significant differences in drying behaviour predictions, where differences of the total drying time with respect to its mean value up to $200 \%$ are found for the materials considered. Therefore, numerical modelling of heat and moisture transport in porous materials should preferably include a quantification of the propagation of these uncertainties, for example by means of the proposed transport-property parameter analysis. Such analysis however additionally requires detailed (a-priori) experimental material characterisation to determine realistic uncertainty ranges.
\end{abstract}


Defraeye T., Blocken B., Carmeliet J. (2013), Influence of uncertainty in heat-moisture transport properties on convective drying of porous materials by numerical modelling, Chemical Engineering Research and Design 91 (1), 36-42. http://dx.doi.org/10.1016/i.cherd.2012.06.011

\section{Introduction}

Heat and mass transport in porous materials is often analysed by means of numerical methods for various industrial drying applications, for food processing, for soil hydrological processes, for hygrothermal analysis of building envelope components, etc. Several numerical modelling approaches have been developed to model this coupled heat and mass transport, such as pore network models (e.g. Carmeliet et al., 1999; Metzger and Tsotsas, 2008; Prat, 1993; Yiotis et al., 2001) or macroscopic models (e.g. Ben Nasrallah and Perre, 1988; Defraeye et al., 2012; Erriguible et al., 2006; Janssen et al., 2007). In macroscopic models the porous material is considered as a continuum, where the transport processes are modelled by numerically solving the macroscopic conservation equations, which require knowledge of several heat-moisture transport properties. These properties are usually determined experimentally, often as a function of the moisture content. Material characterisation is thereby an integral part of numerical modelling with these macroscopic heat-air-moisture transfer (HAM) models. A significant spread on the required transport properties has however been reported when comparing results of different laboratories on multiple material samples (Dominguez-Munoz et al., 2010; Roels et al., 2004; Roels et al., 2010), especially for properties related to moisture transport. The resulting uncertainty in the transport properties originates from: (1) the measurement accuracy of the test setup; (2) material heterogeneity; (3) differences in measuring equipment, measurement protocol and data postprocessing between different laboratories.

The propagation of these transport-property uncertainties to the numerical simulation results of HAM models is often not assessed in detail. Usually, only simple sensitivity analysis of the HAM simulation results to individual transport properties is performed, e.g. by varying each property with a predefined percentage and assessing the impact on the results. Nevertheless, quantifying the influence of transport-property uncertainties, both for individual properties as well as for the ensemble of properties, on the simulation results is strongly recommended when comparing (validating) simulations with experimental data. Assessing this uncertainty propagation analytically is not straightforward since HAM models represent complex, non-linear systems with uncertainties in multiple transport properties. For such complex systems, methods based on Monte Carlo simulation (MCS) are more appropriate. In MCS, a deterministic model (e.g. a HAM model) is applied many times, each time using a random set of multiple input parameters with a certain probability distribution, by which a stochastic model output is generated. Thereby, MCS allows assessing uncertainty propagation of the input parameters by statistical analysis of the stochastic output. MCS however requires a large number of simulations.

Analysis based on the Monte Carlo method has already been applied for various drying applications of porous materials (e.g. Copolla et al., 2009; Cronin and Kearny, 1998; Tanaka et al., 2008). In this paper, the propagation of heat-moisture transport-property uncertainty to the coupled heat and mass transfer (HAM) simulation results of convective drying of a porous material is investigated by means of transport-property parameter analysis (TPPA) based on the Monte Carlo method: the numerical (HAM) model is evaluated for a random set of one or multiple transport-property input parameters, by which a stochastic model output is generated. Such an analysis allows identifying in detail the sensitivity of the specific case to the heat-moisture transport properties. To the knowledge of the authors, such an analysis has not yet been performed. The transport-property uncertainty ranges, which serve as an input for HAM modelling, are estimated based on experimental measurements after 
Defraeye T., Blocken B., Carmeliet J. (2013), Influence of uncertainty in heat-moisture transport properties on convective drying of porous materials by numerical modelling, Chemical Engineering Research and Design 91 (1), 36-42. http://dx.doi.org/10.1016/i.cherd.2012.06.011

which a TP-PA of convective drying of two capillary-saturated materials is performed, namely for ceramic brick and plaster. Afterwards, statistical analysis of the TP-PA output is performed to quantify the impact of these transport-property uncertainties on the drying process.

\section{Methods}

\subsection{Configuration}

The configuration used to evaluate convective drying of a capillary-saturated material is shown in Figure 1. A porous material of $3 \times 1 \times 1 \mathrm{~cm}^{3}$ is considered. All side surfaces and the bottom surface of the material are considered adiabatic and impermeable for moisture. The porous material is assumed to be initially capillary saturated at a temperature of $20^{\circ} \mathrm{C}$ where the top surface is exposed to air flow with an approach flow temperature $\left(T_{a f}\right)$ and relative humidity $\left(R H_{a f}\right)$ of $20^{\circ} \mathrm{C}$ and $50 \%$, respectively. The moisture content at capillary saturation, i.e. not fully saturated, can be determined by a free water uptake test (e.g. Roels et al., 2004). The two materials which are evaluated are ceramic brick and plaster. Both materials are capillary active but only plaster is considered hygroscopic. Detailed thermal and hygric transport properties can be found in Hagentoft et al. (2004) and are also specified in the next section.

\subsection{HAM modelling}

The configuration presented in Figure 1 is used by the HAM model, where only one-dimensional transport is assumed. Convective heat and moisture transfer coefficients (CHTCs and CMTCs) are often used in HAM modelling. They relate the convective heat and moisture flux normal to the wall $\left(q_{c, w}\right.$ and $g_{v, w}$, positive away from the porous material) to the difference between the wall temperature $\left(T_{w}\right)$ or vapour pressure at the wall $\left(p_{v, w}\right)$ and the approach flow temperature $\left(T_{a f}\right)$ or vapour pressure $\left(p_{v, a f}\right)$ : CHTC $=q_{c, w} /\left(T_{w}-T_{a f}\right) ; \mathrm{CMTC}=$ $g_{v, w} /\left(p_{v, w}-p_{v, a f}\right)$. The imposed CHTC and CMTC are $19.9 \mathrm{~W} / \mathrm{m}^{2} \mathrm{~K}$ and $1.41 \times 10^{-7} \mathrm{~s} / \mathrm{m}$, respectively, which are representative for exposure to the outdoor environment. An appropriate 1D mesh is built, based on a mesh sensitivity analysis, consisting of 25 finite elements in the vertical direction with a gradual refinement towards the air-porous material interface. Radiative heat transfer is not considered.

The heat and moisture (liquid and vapour) transport in the material is modelled by means of a finite-element HAM model (see Janssen et al. (2007) for details). Its most important modelling assumptions are that: (1) air transport is not taken into account; (2) vapour transport due to thermal gradients is accounted for, while liquid transport due to thermal gradients is neglected; (3) gravitational effects are neglected compared to capillary liquid transport, hence assuming that no macro pores or cracks are present; (4) the gaseous phase does not contribute to heat or mass storage; (5) moisture storage is independent of temperature; (6) temperatures are well below $100^{\circ} \mathrm{C}$; (7) moisture transfer is driven by gradients in capillary pressure $\left(p_{c}\right)$, i.e. the pressure difference between the gaseous and liquid phase, thus positive for unsaturated conditions.

Apart from these modelling assumptions, the accuracy of HAM models also relies on experimentally-determined transport properties. Following heat-moisture transport properties are typically required in HAM models (e.g. Janssen et al., 2007) and are specified in Table 1 for both porous materials (see Hagentoft et al., 2004): (1) the bulk density of the dry porous material $\left(\rho_{s}\right) ;(2)$ the specific heat capacity of the dry porous material $\left(c_{p, s}\right) ;(3)$ the 
Defraeye T., Blocken B., Carmeliet J. (2013), Influence of uncertainty in heat-moisture transport properties on convective drying of porous materials by numerical modelling, Chemical Engineering Research and Design 91 (1), 36-42. http://dx.doi.org/10.1016/i.cherd.2012.06.011

thermal conductivity of the porous material $\left(\lambda_{P M}\right)$, which is a function of the moisture content; (4) the vapour diffusion coefficient of the porous material $\left(\delta_{v}\right) ;(5)$ the liquid permeability of the porous material $\left(K_{l}\right.$, Figure 2$)$; (6) the moisture retention curve (Figure 2), which relates the capillary pressure to the moisture content $(w)$. The first three properties are related to heat transfer and storage, where the last three are related to moisture transfer and storage (both liquid and vapour).

\subsection{Transport-property parameter analysis}

The TP-PA presented in this study is based on the Monte Carlo method: the HAM model is evaluated many times, each time using a random set of one specific input parameter or of multiple parameters, i.e. heat-moisture transport properties, with a certain probability distribution. Thereby, a stochastic HAM model output is generated for a specific transport property, or for an ensemble of transport properties. Two types of TP-PA are performed: (1) One input parameter is varied randomly, whereas the others are kept constant. Such an analysis is performed for each input parameter; (2) All input parameters are varied simultaneously. The chosen stochastic input parameters (i.e. heat-moisture transport properties) for the TP-PA with the HAM model are $\rho_{s}, c_{p, s}, \lambda_{P M}$, $\mu_{d r y}, w_{c a p}$ and $K_{l}$. Here, $\mu_{d r y}$ is used instead of $\delta_{v}$ since $\mu_{d r y}$ is actually measured. Furthermore, stochastics in the moisture retention curve are assumed to be accounted for by $w_{c a p}$, which imposes a vertical shift (see Figure 2). Reliable estimates of uncertainty ranges of these transport properties are required to ensure a realistic stochastic TP-PA output. These uncertainties should comprise the influence of material heterogeneity and measurement accuracy of the test setup. Normally, such uncertainties result from a detailed experimental characterisation of a specific material. Such an extensive experimental study was not within the scope of this study, but rather representative ranges of uncertainties were required for the TP-PA. Therefore, the transport-property uncertainties used in the TP-PA are chosen in a rather pragmatic way and are specified in detail below for ceramic brick. Similar uncertainties are chosen for plaster to allow a proper comparison between the TP-PA results of both materials, although in reality these uncertainties are to some extent material dependent.

Due to the dependency of the transport properties on the material pore structure and the moisture content, complex cross-correlations between the transport properties exists, which are difficult to establish uniformly. An analysis of the influence of these correlations was not within the scope of this TP-PA study, and representative uncertainty ranges were already considered sufficient for this study. Such ranges allow assessing the sensitivity of the specific case, i.e. convective drying of a porous material, to the different transport properties. Therefore, for simplicity, all transport-property input parameters in this study are assumed to be normally distributed and uncorrelated, apart from the correlation of $\delta_{v}$ with $w_{c a p}$, which is rather weak, and the correlation of $\lambda_{P M}$ with the moisture content. Thereby, the transport-property uncertainties can be characterised by standard deviations on the mean values, which are specified in Table 1 . The standard deviations on $\rho_{s}, \mu_{d r y}$ and $w_{c a p}$ are based on measurements on multiple ceramic brick samples by different laboratories (Roels et al., 2004). The relatively high standard deviation for $\mu_{d r y}$ is mainly attributed to the measurement technique (Roels et al., 2004), where similar high values were also found by Roels et al. (2010) for gypsum board. The standard deviations on $c_{p, s}$ and $\lambda_{P M}$ are based on in-house measurements. The standard deviation on the $\log \left(K_{l}\right)-\log \left(p_{c}\right)$ distribution is estimated to be $1 \%$ in vertical and horizontal direction (on a log-log scale, as indicated in Figure 2). This uncertainty in $K_{l}$ mainly originates from: (1) the measurement error of the test setup; (2) material heterogeneity within a specific 
Defraeye T., Blocken B., Carmeliet J. (2013), Influence of uncertainty in heat-moisture transport properties on convective drying of porous materials by numerical modelling, Chemical Engineering Research and Design 91 (1), 36-42. http://dx.doi.org/10.1016/i.cherd.2012.06.011

sample; (3) material heterogeneity between different samples; (4) approximation/ smoothing of the liquid diffusivity curve. More information on the determination of $K_{l}$ for porous materials (out of the liquid diffusivity) can be found in Carmeliet et al. (2004).

With the mean values, standard deviations and probability distributions of the input parameters, random sets of one or multiple transport properties can be generated for TP-PA with the HAM model. To obtain a reliable stochastic output, sufficient HAM simulations are required. By means of a sensitivity analysis on the number of simulations, i.e. by monitoring the output statistics, 2000 HAM simulations are found to be sufficient. In addition to the transport-property uncertainties, some uncertainty on the boundary conditions imposed at the airmaterial interface (convective and radiative) also exists in reality, where the impact of these uncertainties on HAM simulation results can also be analysed by a similar parameter analysis, based on the Monte Carlo method. Since this is outside the scope of this study, the convective boundary conditions (CHTC and CMTC together with $T_{a f}$ and $p_{v, a f}$ ) are assumed deterministic.

\section{Results and discussion}

Before analysing the TP-PA results, the general characteristics of the drying process of porous materials are briefly discussed. After an initial transition period, the material goes to an equilibrium condition, i.e. the constant drying rate period (CDRP), given that the air-material interface remains wet. The CDRP is characterised by a relative humidity of $100 \%$ at the surface, a constant drying rate and a constant material temperature, namely the wet bulb temperature $\left(T_{w b}\right)$. As evaporation occurs at the air-porous material interface, the drying rate is characterised by the air-flow conditions and not by the material transport properties. Nevertheless, the transport properties do affect the length of the CDRP, since it is dependent on the liquid transport to the surface. When the material dries out locally at the interface, the decreasing drying rate period (DDRP) sets in, which is characterised by a lower drying rate since the "dry" outer porous-material layer forms an additional resistance to liquid water removal from the inside of the material towards the interface, in addition to the boundary-layer resistance. During the DDRP, the drying rate is thereby much less sensitive to the convective boundary conditions.

First, the TP-PA results where all input parameters are randomly varied simultaneously are discussed. The TPPA statistics (mean, median, minimal and maximal values as well as the 5\% and 95\% quantiles) of the dimensionless drying rates $\left(g_{v, w} / g_{v, w, r e f}\right)$ for both materials as a function of dimensionless time $\left(t / t_{t o t}\right)$ are shown in Figure 3, where the total simulation times $\left(t_{t o t}\right)$ for ceramic brick and plaster are 5 and 15 days, respectively. The drying rates are made dimensionless with the mean drying rate at $t / t_{t o t}=0.05$, namely $g_{v, w, r e f}$. Note that the initial moisture content of the porous material differs for each HAM simulation since it is capillary saturated at $w=$ $w_{c a p}$, which is a stochastically-variable input parameter. The TP-PA statistics of the surface temperature $\left(T_{w}\right.$, in $\left.{ }^{\circ} \mathrm{C}\right)$, scaled with the mean temperature at $t / t_{\text {tot }}=0.05\left(T_{\text {ref }}\right.$, in $\left.{ }^{\circ} \mathrm{C}\right)$, are shown in Figure 4 , together with those of the relative humidity $(\mathrm{RH})$ at the surface. Note that the reported median values, but not the mean values, agree well with the solution which is obtained by a HAM simulation using the mean transport properties of Table 1 (simulation results not shown here). 
Defraeye T., Blocken B., Carmeliet J. (2013), Influence of uncertainty in heat-moisture transport properties on convective drying of porous materials by numerical modelling, Chemical Engineering Research and Design 91 (1), 36-42. http://dx.doi.org/10.1016/i.cherd.2012.06.011

Ceramic brick clearly shows a CDRP (Figure 3 and Figure 4), where $T_{\text {ref }}$ equals the wet bulb temperature and $g_{v, w, r e f}$ equals the CDRP drying rate, which are the same for all HAM simulations since they are only dependent on the convective boundary conditions. A significant spread on the TP-PA results is found, where the duration of the CDRP ranges from $t / t_{t o t} \approx 0.05-0.2$ and differences of the total drying time with respect to its mean value up to $200 \%$ are found. Plaster does not show a CDRP since it quickly dries out at the surface because the supply of liquid water to the surface cannot keep up with the convective moisture removal due to its relatively low liquid permeability (Figure 2). Thereby, a much longer drying time is found although the same convective boundary conditions as for ceramic brick are used. The spread on the TP-PA results is also rather limited for plaster.

The presented TP-PA results do not allow identifying the sensitivity of the stochastic model output to an individual input parameter, but only show their ensemble effect. To identify this individual sensitivity, also a TPPA is performed where only one specific transport property is allowed to vary stochastically, namely the vapour diffusion coefficient $\left(\delta_{v}\right.$, thus $\mu_{d r y}$ ), the moisture retention curve (thus $\left.w_{c a p}\right)$, the liquid permeability $\left(K_{l}\right)$ or the thermal properties $\left(\rho_{s}, c_{p, s}, \lambda_{P M}\right)$. The resulting dimensionless drying rates are presented in Figure 5 for ceramic brick and plaster. Assessing these individual sensitivities will help explain the causes for the spread found in Figure 3 and Figure 4, i.e. where the ensemble of input parameters was taken variable.

For both materials, the influence of varying thermal properties on the TP-PA output was negligible for this specific HAM problem, which is why they are not shown. Furthermore, the spread on the drying rate with varying moisture retention curve (thus $w_{\text {cap }}$ ) is mainly caused by differences in initial moisture contents. For ceramic brick, the spread on the TP-PA results of Figure 3 can be mainly attributed to the liquid permeability (Figure $5 \mathrm{~b}$ ), since liquid transport mainly determines the drying rate, where the sensitivity to vapour diffusion transport $\left(\mu_{d r y}\right)$ is very small, except at the end of the drying process (see Figure $5 \mathrm{c}$ ). When comparing the liquid permeability with the total moisture permeability in Figure 6a together with the moisture retention curve, it is clear that when moisture transport by vapour diffusion starts to have an impact on the permeability (at $p_{c} \approx 10^{7.5}$ ), the brick is quasi completely dry. For plaster, the spread on the TP-PA results of Figure 3 can be attributed to vapour diffusion since the material dries out quickly at the surface, by which vapour transport (DDRP) also determines the kinetics of moisture removal. When moisture transport by vapour diffusion starts to have an impact on the total moisture permeability (at $p_{c} \approx 10^{7}$ ), a considerable amount of moisture is still present in the material (Figure 6b).

\section{Conclusions}

The propagation of heat-moisture transport-property uncertainty in HAM simulation of convective drying of two capillary-saturated porous materials, namely ceramic brick and plaster, was investigated by means of a transportproperty parameter analysis (TP-PA) based on the Monte Carlo method. Here, stochastic HAM model output is generated by evaluating the model many times, each time using a random set of one or multiple input parameters (i.e. heat-moisture transport-properties). Reliable estimates of transport-property uncertainty ranges were used as stochastic TP-PA input and their impact on the TP-PA output statistics was analysed. A significant spread on the TP-PA output (drying rate, surface temperature and relative humidity) was found for ceramic brick but to a much lesser extent for plaster. Sensitivity analysis of HAM simulations to individual transport properties identified that 
Defraeye T., Blocken B., Carmeliet J. (2013), Influence of uncertainty in heat-moisture transport properties on convective drying of porous materials by numerical modelling, Chemical Engineering Research and Design 91 (1), 36-42. http://dx.doi.org/10.1016/i.cherd.2012.06.011

the drying behaviour of ceramic brick and plaster was most sensitive to liquid transport and combined liquid and vapour transport parameters, respectively. The sensitivity to thermal properties was found to be negligible for this specific HAM problem.

The TP-PA results clearly indicated that transport-property uncertainty, due to measurement errors and material heterogeneity, can lead to significant differences in drying behaviour predictions, where the sensitivity to certain transport properties is strongly material dependent. It is therefore always advised to assess the propagation of these uncertainties to the results of a HAM simulation, for example by means of TP-PA, especially when comparing HAM simulations with experiments. Since reliable estimates of these uncertainties are however required, which inherently implies a detailed experimental characterisation, and since many HAM simulations are required for TP-PA, such an analysis is very time consuming, especially for $2 \mathrm{D}$ and $3 \mathrm{D}$ problems, and is thereby usually not performed. Although the influence of transport-property uncertainty on HAM simulation results is therefore often left unacknowledged, more attention should be invested in the future on this aspect of HAM studies, as indicated by the present study.

\section{Acknowledgements}

Thijs Defraeye is a postdoctoral fellow of the Research Foundation - Flanders (FWO) and acknowledges its support. This sponsor had no involvement in: the study design, the collection, analysis and interpretation of data; the writing of the manuscript; and the decision to submit the manuscript for publication.

\section{References}

Ben Nasrallah, S., Perre, P., 1988. Detailed study of a model of heat and mass transfer during convective drying of porous media. Int. J. Heat Mass Tran. 31(5), 957-967.

Carmeliet, J., Descamps, F., Houvenaghel, G., 1999. A multiscale network model for simulating moisture transfer properties of porous media. Transport Porous Med. 35, 67-88.

Carmeliet, J., Hens, H., Roels, S., Adan, O., Brocken, H., Cerny, R., Pavlik, Z., Hall, C., Kumaran, K., Pel, L., 2004. Determination of the liquid water diffusivity from transient moisture transfer experiments. J. Thermal Envelope Building Sci. 27(4), 277-305.

Coppola, A., Basile, A., Comegna, A., Lamaddalena, N., 2009. Monte Carlo analysis of field water flow comparing uni- and bimodal effective hydraulic parameters for structured soil. J. Contam. Hydrol. 104(1-4), $153-165$.

Cronin, K., Kearney, S., 1998. Monte Carlo modelling of a vegetable tray dryer. J. Food Eng. 35(2), 233-250.

Defraeye, T., Blocken, B., Carmeliet, J., 2012. Analysis of convective heat and mass transfer coefficients for convective drying of a porous flat plate by conjugate modelling. International Journal of Heat and Mass Transfer 55 (1-3), 112-124.

Dominguez-Munoz, F., Anderson, B., Cejudo-Lopez, J.M., Carrillo-Andres, A., 2010. Uncertainty in the thermal conductivity of insulation materials. Energ. Buildings 42(11), 2159-2168.

Erriguible, A., Bernada, P., Couture, F., Roques, M., 2006. Simulation of convective drying of a porous medium with boundary conditions provided by CFD. Chem. Eng. Res. Des. 84 (2), 113-123. 
Defraeye T., Blocken B., Carmeliet J. (2013), Influence of uncertainty in heat-moisture transport properties on convective drying of porous materials by numerical modelling, Chemical Engineering Research and Design 91 (1), 36-42. http://dx.doi.org/10.1016/i.cherd.2012.06.011

Hagentoft, C.E., Kalagasidis, A.S., Adl-Zarrabi, B., Roels, S., Carmeliet, J., Hens, H., Grunewald, J., Funk, M., Becker, R., Shamir, D., Adan, O., Brocken, H., Kumaran, K., Djebbar, R., 2004. Assessment method of numerical prediction models for combined heat, air and moisture transfer in building components: benchmarks for one-dimensional cases. J. Therm. Envelope Building Sci. 27(4), 327-352.

Janssen, H., Blocken, B., Carmeliet, J., 2007. Conservative modelling of the moisture and heat transfer in building components under atmospheric excitation. Int. J. Heat Mass Tran. 50(5-6), 1128-1140.

Metzger, T., Tsotsas, E., 2008. Viscous stabilization of drying front: Three-dimensional pore network simulations. Chem. Eng. Res. Des. 86(7), 739-744.

Prat, M., 1993. Percolation model of drying under isothermal conditions in porous media. Int. J. Multiphas. Flow 19(4), 691-704.

Roels, S., Carmeliet, J., Hens, H., Adan, O., Brocken, H., Cerny, R., Pavlik, Z., Hall, C., Kumaran, K., Pel, L., Plagge, R., 2004. Interlaboratory comparison of hygric properties of porous building materials. J. Therm. Envelope Building Sci. 27, 307-325.

Roels, S., Talukdar, P., James, C., Simonson, C.J., 2010. Reliability of material data measurements for hygroscopic buffering. Int. J. Heat Mass Tran. 53(23-24), 5355-5363.

Tanaka, F., Maeda, Y., Uchino, T., Hamanaka, D., Atungulu, G.G., 2008. Monte Carlo simulation of the collective behavior of food particles in pneumatic drying operation. LWT - Food Sci. Technol. 41(9), 15671574.

Yiotis, A.G., Stubos A.K., Boudouvis, A.G., Yortsos, Y.C., 2001. A 2-D pore-network model of the drying of single-component liquids in porous media. Adv. Water Resour. 24(3-4), 439-460. 
Defraeye T., Blocken B., Carmeliet J. (2013), Influence of uncertainty in heat-moisture transport properties on convective drying of porous materials by numerical modelling, Chemical Engineering Research and Design 91 (1), 36-42. http://dx.doi.org/10.1016/i.cherd.2012.06.011

\section{Figure captions}

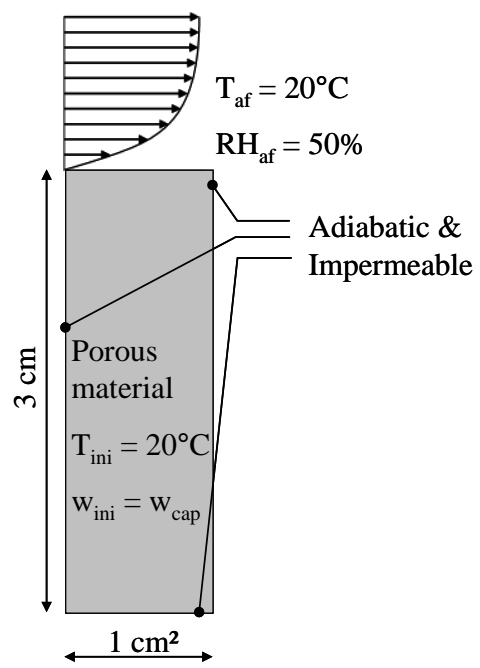

Figure 1. Computational model for numerical analysis of convective drying of a capillary-saturated porous material (subscript ${ }_{\text {cap }}$ ) with initial (subscript ${ }_{\mathrm{ini}}$ ) and boundary conditions ( $w$ is the moisture content).
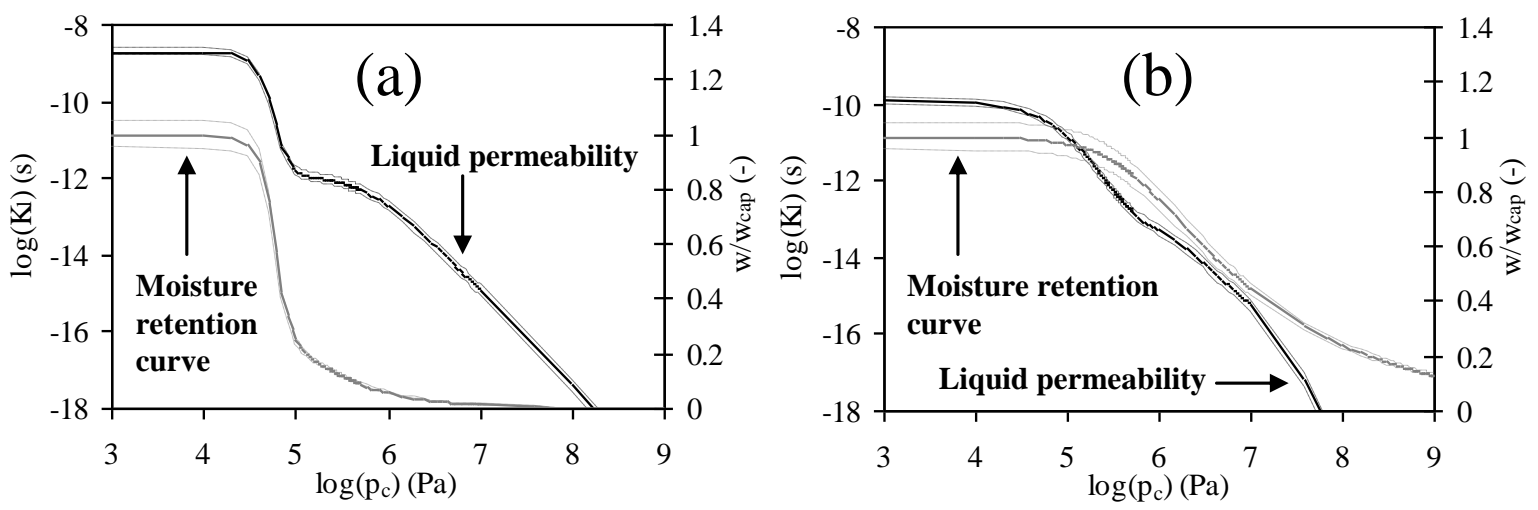

Figure 2. Mean moisture retention curve (full grey line), scaled with $w_{c a p}$, and logarithm of the mean liquid permeability (full black line) as a function of the logarithm of the capillary pressure together with the standard deviations specified in Table 1 (dotted lines) for: (a) ceramic brick; (b) plaster.
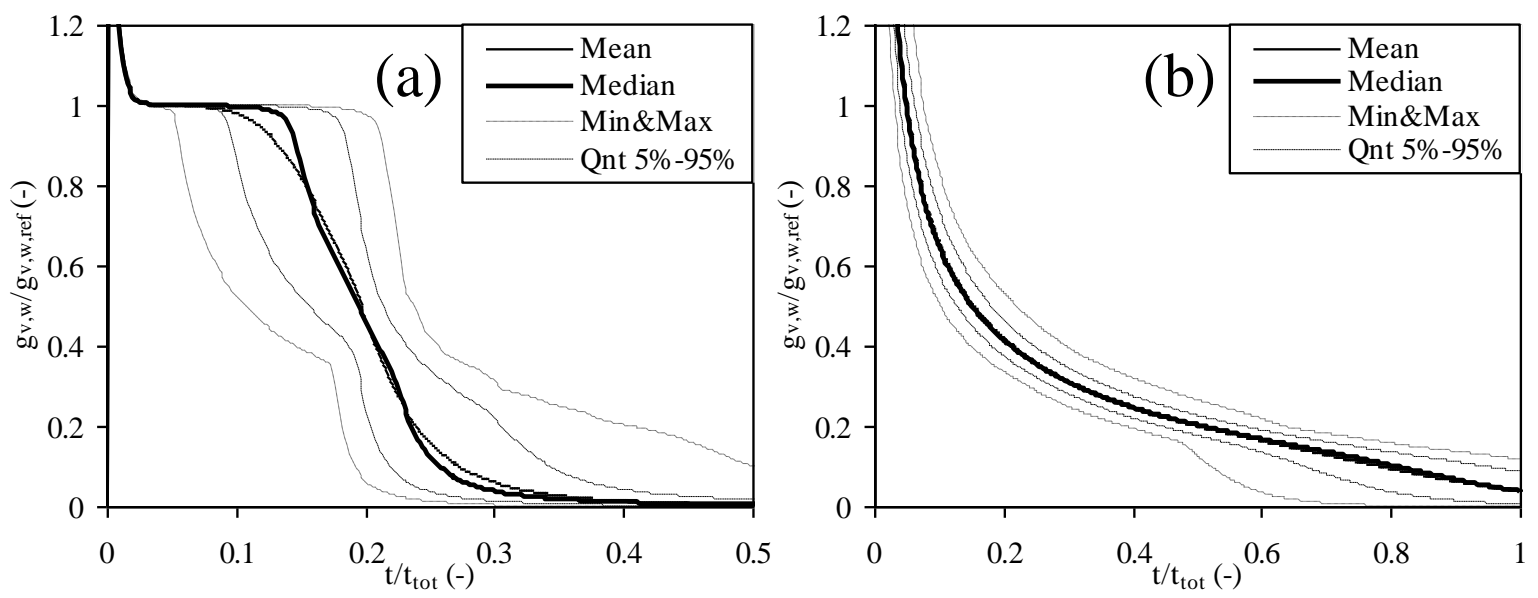
Defraeye T., Blocken B., Carmeliet J. (2013), Influence of uncertainty in heat-moisture transport properties on convective drying of porous materials by numerical modelling, Chemical Engineering Research and Design 91 (1), 36-42. http://dx.doi.org/10.1016/i.cherd.2012.06.011

Figure 3. TP-PA statistics (mean, median, minimal, maximal values and $5 \%$ and $95 \%$ quantiles) of scaled drying rate, as a function of scaled time, for: (a) ceramic brick; (b) plaster.
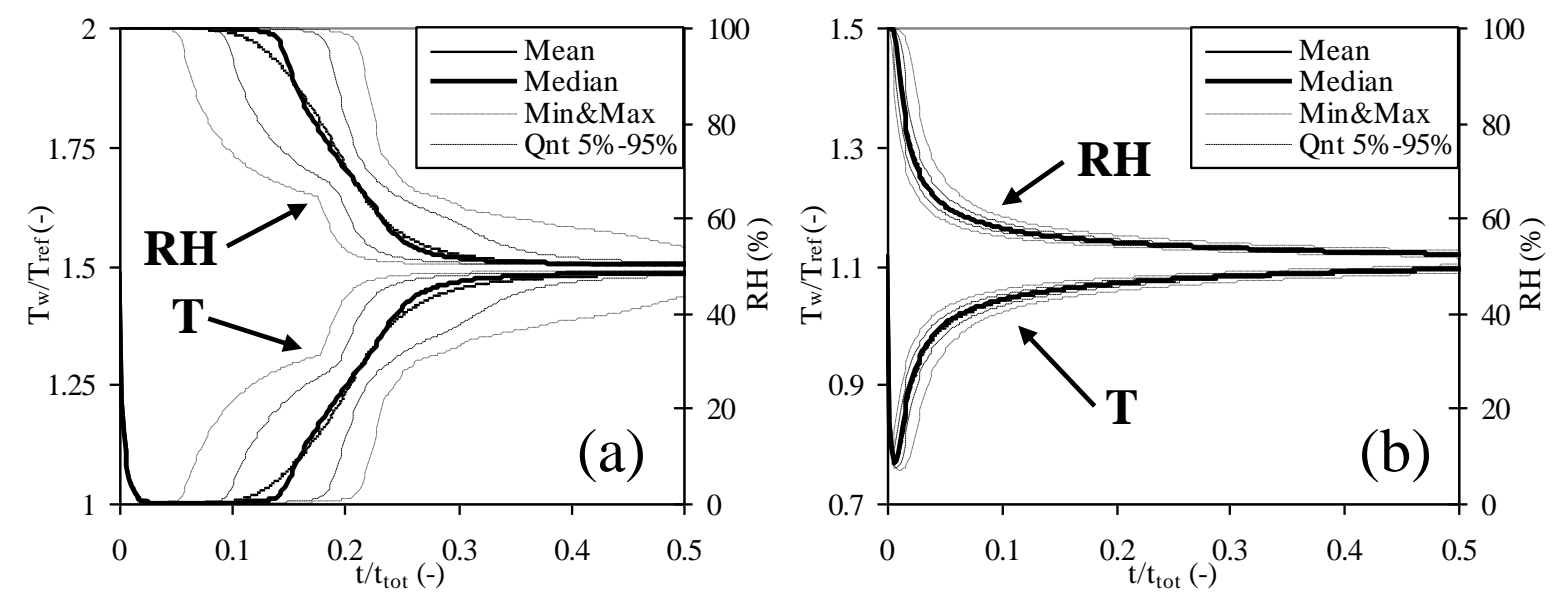

Figure 4. TP-PA statistics (mean, median, minimal, maximal values and $5 \%$ and $95 \%$ quantiles) of scaled surface temperature and relative humidity at the surface, as a function of scaled time, for: (a) ceramic brick; (b) plaster. 
Defraeye T., Blocken B., Carmeliet J. (2013), Influence of uncertainty in heat-moisture transport properties on convective drying of porous materials by numerical modelling, Chemical Engineering Research and Design 91 (1), 36-42. http://dx.doi.org/10.1016/i.cherd.2012.06.011
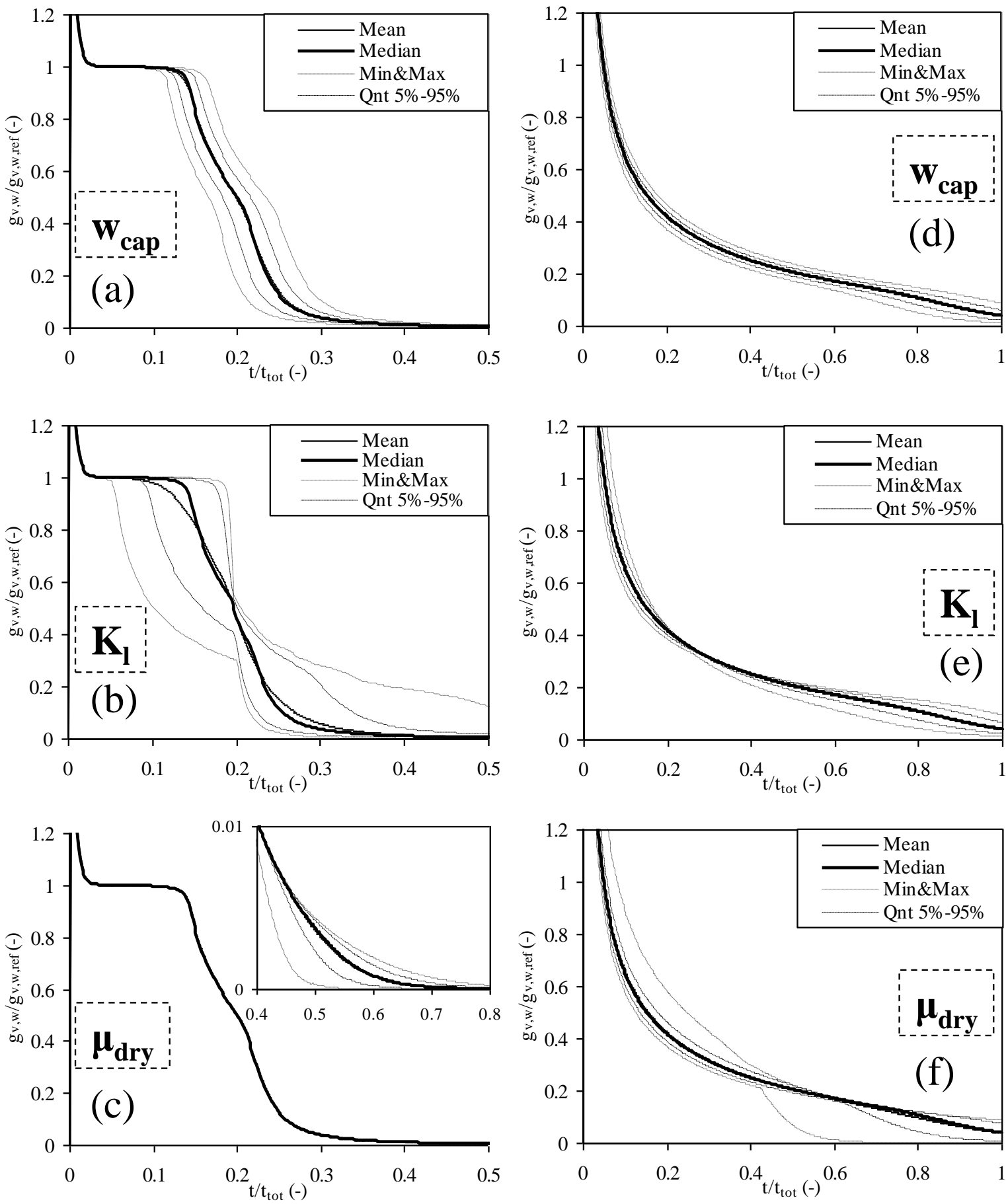

Figure 5. TP-PA statistics (mean, median, minimal, maximal values and $5 \%$ and $95 \%$ quantiles) of scaled drying rate, as a function of scaled time, for ceramic brick (a-c) and plaster (d-f) for different stochastically varying input parameters, namely $w_{c a p}(\mathrm{a \& d}), K_{l}(\mathrm{~b} \& \mathrm{e})$ and $\mu_{d r y}(\mathrm{c} \& \mathrm{f})$. 
Defraeye T., Blocken B., Carmeliet J. (2013), Influence of uncertainty in heat-moisture transport properties on convective drying of porous materials by numerical modelling, Chemical Engineering Research and Design 91 (1), 36-42. http://dx.doi.org/10.1016/i.cherd.2012.06.011
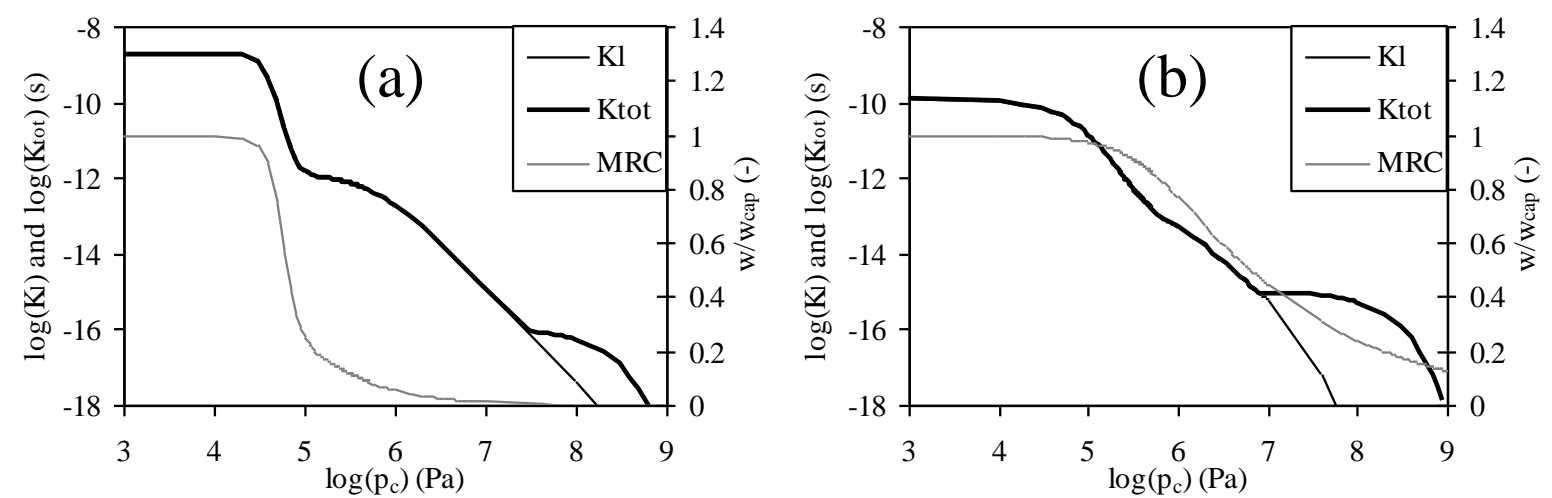

Figure 6. Moisture retention curves (MRC, grey line), scaled with $w_{c a p}$, and logarithm of the liquid ( $K_{l}$, black line) and total moisture permeability's ( $K_{t o t}$, bold black line) as a function of the logarithm of the capillary pressure for: (a) ceramic brick; (b) plaster. 
Defraeye T., Blocken B., Carmeliet J. (2013), Influence of uncertainty in heat-moisture transport properties on convective drying of porous materials by numerical modelling, Chemical Engineering Research and Design 91 (1), 36-42. http://dx.doi.org/10.1016/i.cherd.2012.06.011

\section{Tables}

Table 1. Transport properties of ceramic brick and plaster used in HAM model: mean values and standard deviations used in TP-PA.

\begin{tabular}{|c|c|c|c|}
\hline Property & Mean value ceramic brick & Mean value plaster & Standard deviation \\
\hline$\rho_{s}\left(\mathrm{~kg} / \mathrm{m}^{3}\right)$ & 2005 & 790 & $1 \%$ \\
\hline$c_{p, s}(\mathrm{~J} / \mathrm{kgK})$ & 840 & 870 & $5 \%$ \\
\hline$\lambda_{P M}(\mathrm{~W} / \mathrm{mK})$ & $0.5+0.0045 w$ & $0.2+0.0045 w$ & $5 \%$ \\
\hline \multirow[t]{2}{*}{$\delta_{v}(\mathrm{~s})$} & \multirow{2}{*}{$\frac{2.61 \cdot 10^{-5}}{\mu_{\text {dry }} \mathrm{R}_{\mathrm{v}} \mathrm{T}} \frac{1-\left(\mathrm{w} / \mathrm{w}_{\text {cap }}\right)}{0.503\left(1-\left(\mathrm{w} / \mathrm{w}_{\text {cap }}\right)\right)^{2}+0.497}$} & \multirow{2}{*}{$\frac{2.61 \cdot 10^{-5}}{\mu_{\text {dry }} \mathrm{R}_{\mathrm{v}} \mathrm{T}} \frac{1-\left(\mathrm{w} / \mathrm{w}_{\text {cap }}\right)}{0.503\left(1-\left(\mathrm{w} / \mathrm{w}_{\text {cap }}\right)\right)^{2}+0.497}$} & \multirow[t]{2}{*}{$18 \%$ on $\mu_{d r y}$} \\
\hline & & & \\
\hline$w\left(\mathrm{~kg} / \mathrm{m}^{3}\right)$ & $\mathrm{w}_{\text {cap }}\left[\begin{array}{l}0.3\left(1+\left(1.25 \cdot 10^{-5} \mathrm{p}_{\mathrm{c}}\right)^{1.65}\right)^{-0.65 / 1.65} \\
+0.7\left(1+\left(1.80 \cdot 10^{-5} \mathrm{p}_{\mathrm{c}}\right)^{6}\right)^{-5 / 6}\end{array}\right]$ & $\mathrm{w}_{\mathrm{cap}}(1+$ & $5 \%$ on $w_{c a p}$ \\
\hline$K_{l}(\mathrm{~s})$ & see Figure 2 & see Figure 2 & $\begin{array}{c}1 \% \text { on } K_{l} \text { and } 1 \% \text { on } \\
p_{c} \text { on } \log -\log \text { scale }\end{array}$ \\
\hline $\begin{array}{l}\mu_{d r y}: \text { vapour } \mathrm{r} \\
\mathrm{J} / \mathrm{kgK}) ; w_{c a p}:\end{array}$ & $\begin{array}{l}\text { nce factor of the porous material ( } 30 \text { for cera } \\
\text { ary moisture content }\left(157 \mathrm{~kg} / \mathrm{m}^{3} \text { for ceramic }\right.\end{array}$ & $\begin{array}{l}\text { orick, } 3 \text { for plaster); } R_{v}: \text { specific gas consta } \\
; ; 209 \mathrm{~kg} / \mathrm{m}^{3} \text { for plaster); } T \text { : temperature in }\end{array}$ & $\begin{array}{l}\text { f water vapour }(462 \\
\text { lvin. }\end{array}$ \\
\hline
\end{tabular}

